\title{
Resisting the Medicalisation of Menopause: Reclaiming the Body through Design
}

\author{
Marianela Ciolfi Felice \\ ciolfi@kth.se \\ KTH Royal Institute of Technology \\ Stockholm, Sweden
}

\author{
Marie Louise Juul Søndergaard \\ mljso@kth.se \\ KTH Royal Institute of Technology \\ Stockholm, Sweden
}

\author{
Madeline Balaam \\ balaam@kth.se \\ KTH Royal Institute of Technology \\ Stockholm, Sweden
}

\begin{abstract}
The menopause transition involves bodily-rooted, socially-shaped changes, often in a context of medicalisation that marginalises people based on their age and gender. With the goal of addressing this social justice matter with a participatory design approach, we started to cultivate partnerships with people going through menopause. This paper reports on interviews with 12 women and a design workshop with three. Our data analysis highlights their experiences from a holistic perspective that reclaims the primacy of the body and acknowledges the entanglement of the physical and the psychosocial. Participants' design concepts show how design can come close the body to make space for menopause experiences, recognising and transforming them. We discuss how HCI can actively engage with the body to promote appreciation for it during menopause, and call for design that accompanies people in resisting the medicalisation of menopause as an enactment of social justice in everyday life.
\end{abstract}

\section{CCS CONCEPTS}

- Human-centered computing $\rightarrow$ Human computer interaction (HCI); Interaction design; Participatory design.

\section{KEYWORDS}

menopause, women's health, feminist research, soma design

\section{ACM Reference Format:}

Marianela Ciolfi Felice, Marie Louise Juul Søndergaard, and Madeline Balaam. 2021. Resisting the Medicalisation of Menopause: Reclaiming the Body through Design. In CHI Conference on Human Factors in Computing Systems (CHI '21), May 8-13, 2021, Yokohama, Japan. ACM, New York, NY, USA, 16 pages. https://doi.org/10.1145/3411764.3445153

\section{INTRODUCTION}

The transition to menopause, or climacteric, comes with a range of bodily experiences that are socially shaped and typically happen in the broader context of midlife. Accepting one's body as it changes is crucial for positive experiences of the climacteric [37, 78], and a healthy transition is indeed key for quality of life, and in the long term, for a healthy ageing process. However, a narrow view on health contributed to the medicalisation of this normal part of life

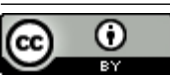

This work is licensed under a Creative Commons Attribution International 4.0 License.

CHI '21, May 8-13, 2021, Yokohama, Japan

(C) 2021 Copyright held by the owner/author(s)

ACM ISBN 978-1-4503-8096-6/21/05.

https://doi.org/10.1145/3411764.3445153
$[12,65]$. Medicalising a phenomenon means defining it as a problem, and more specifically, as a medical problem [24]. The Western biomedical discourse characterises menopause as a hormone deficiency, a condition that requires management, where management equates pharmacological treatment. This framing has placed the responsibility to stay healthy on the individual, while still under the control of medicine. The medicalisation of menopause (and tying it to gender) reduces the experience to a list of 'symptoms' without taking their context into account, pathologising women's health, reproductive life and ageing processes, and constructing women as an Other with respect to a male norm, marginalising them [81] and more broadly, anyone who is not a cisgender man. Moreover, adhering to a medicalised view of menopause was found to negatively affect people's attitudes and lived experiences ([35] provides an overview), while resisting such view was associated to more positive outcomes [37, 78].

Although half of the world's population has gone or will go through menopause (including trans women who stop their intake of oestrogen at midlife), this topic has remained unexplored in HCI for many years. Recently, Bardzell et al. [9], Homewood [46], and Tutia et al. [97] critiqued existing and potential technologies for menopause, showing that a solutionist approach is particularly dangerous as it risks essentialising the experience and furthering marginalisation.

Given the intersecting gender- and age-based marginalisation that people going through menopause still experience, we recognise it as a social justice matter, in line with Lazar et al. [61]. As feminist design researchers, we intend to foster societal change through design. In this paper, we start with the premise that designing for menopause should engage with the body and promote acceptance and appreciation for it; and that design should accompany people in resisting the medicalisation discourse, and therefore in enacting social justice. Inspired by a Digital Women's Health agenda $[1,7]$ and the Feminist HCI framework [10], we adopt a participatory design approach to involve people with experiences of menopause as active actors in the design process. Answering to Bennett and Rosner's call [13], we start cultivating partnerships, first through interviews with 12 participants and then through a design workshop with three, inspired by soma design methods [48]. Through our analysis, we present menopause as both bodily-rooted and socially-shaped. We discuss how the concepts developed by participants during a workshop, the cocoon and the spike mat, come close the body to make space for menopause experiences, not only recognising but also transforming them. We conclude that making space for menopausal experiences requires the feminist reclaiming of the primacy of the body, and argue that design can support this practice by appreciating the ever-changing body. 


\section{BACKGROUND AND RELATED WORK}

Menopause is traditionally considered a marker for the end of the reproductive cycle in people with menstruating bodies, as their ovaries decrease the production of oestrogen and stop ovulating. Median age presents high geographical and socioeconomic variation, but lies between 42 and 53 years old [77]. The years leading to menopause where the first bodily changes are experienced are called 'peri-menopause'. However, in English, the term menopause is also popularly associated with the whole transition. Clinically, 'natural' menopause is identified retrospectively as the absence of menstruation for 12 consecutive months. This definition is partial, as it does not account for medically 'induced' menopause, where menstruation stops as a result of the removal of the ovaries, chemotherapy, or damaging radiation. It is also ambiguous, since the absence of menstruation for a year is not a unique feature of neither natural nor induced menopause: It can happen to people outside of the climacteric process, either temporarily (e.g., due to pregnancy and breastfeeding, stress, malnutrition, or medical treatments for conditions such as endometriosis) or permanently (when getting the uterus removed while keeping the ovaries). On top of this, tying the definition of menopause solely to the menstrual cycle is problematic. Linking menstruation to womanhood has historically marginalised people who menstruate but are not women, such as trans men, and some intersex and non-binary individuals. Confounding gender and sex has also marginalised women who do not menstruate, such as trans women, but do experience ageist and gender-based discrimination at midlife, as well as the consequences of decreasing or abandoning hormone-replacement therapies (HRT). Menopause and midlife experiences of transgender people have been systematically excluded from medical research and are now starting to be portrayed in specialised scholarship (see, e.g. [25, 73, 86, 104]). Most research on menopause has been conducted with white, English-speaking, middle-class, cisgender, heterosexual, married women, with some notable exceptions (e.g., $[3,4,21,29,44,71,72,78,98,102])$. We use the term women when citing previous research if the samples only included women.

\subsection{Biomedical and feminist narratives of menopause}

Some people going through menopause need to be medicated to ease associated discomfort -the valuable role of medicine here is undeniable. However, medicating a patient for a specific problem that disturbs them is not the same as framing an entire life transition as a problem, and moreover, as a medical problem. According to Conrad and Schneider [24], medicalisation occurs on three levels: the conceptual, when a medical vocabulary or model is used to define a problem; the institutional, when organisations legitimate a problem as a medical one, becoming gatekeepers; and the doctor-patient interaction, when doctors define a patient's experiences as medical problems and provide diagnosis and treatment. The Western biomedical tradition has been collecting a list of signs reported by cisgender women going through menopause. The most common include hot flushes (a sudden feeling of heat with sweating and rapid heartbeat), sleep disturbances due to night sweats, weight gain, memory decline, vaginal dryness, headaches, joint pain, increased variability in energy levels, mood, and libido, and changes in the menstrual cycle. Yet, many of these are not exclusive of menopause, and some not even of people with menstruating bodies [81]. Moreover, varying levels of hormones and menstrual irregularity are seen as normal during adolescence but framed as 'symptoms' at midlife [30].

Social scientists and feminist scholars, on the other hand, have criticised the biomedical approach for emphasising bodily changes in isolation and for portraying an overly negative view of menopause (see, e.g., [35]). They have shown instead that each woman's experience of menopause is unique, as it is a combination of biological and psychosocial factors, and varies with culture, generation, and social location $[29,66,99]$. This body of literature emphasised that menopause can be lived as a positive, negative, or neutral transition depending on beliefs and expectations, life circumstances and broader societal views $[5,36,56,61,103]$. Furthermore, researchers found that adhering to the biomedical narrative negatively affects women's attitudes and lived experiences of menopause ([35] provides a review), whereas resisting this narrative yields more positive outcomes [37, 78]. For many women, the climacteric experience is marked by uncertainty and lack of knowledge [15, 34, 80], often in a context of stigma and taboo [22, 60, 75]. Upholding societal ideals of beauty and gender -by women themselves or by their loved ones- can impact women's sense of identity and relationship to their bodies [35], whose public appearance and behaviour are deemed 'uncontrollable' and 'abnormal' [23, 33]. In contrast, in some contexts menopause may come with a newly acquired freedom and higher social status for women [57, 90, 102], suggesting that the menstruating body has a lower hierarchy and that women's social roles are still defined by their reproductive ability. In some cultures, menopause is commonly associated with a feeling of relief from the fear of being pregnant, from inconveniences related to menstrual cycles and their concealment (e.g. having to carry pads or tampons, avoiding to stain clothes, etc.), and from having to raise children $[8,15,51,64]$-all matters of care that continue to be largely assigned to women.

Some authors have noticed the reluctance of the feminist counternarrative to highlight bodily changes during menopause [28, 35, 52], as if doing so would deny the influence of society and contribute to the consolidation of an oppressive biomedical approach. Engebretson and Wardell [37], studying the experiences of peri-menopausal women, explored their feelings of alienation in the context of the (patriarchal) Western world. They argued that a postmodern feminist paradigm is one that recognises the body as a legitimate source of self-knowledge and experience, rejecting Western mind-body duality. We add to this line of work, which found that approaching menopause from this alternative perspective helped women in accepting and trusting their bodies. Importantly, we do not deny the importance and value of medical knowledge. Our approach, instead, highlights a historical imbalance regarding the role of selfknowledge and the body during menopause, and advocates for the recognition of people's wellbeing strategies and practices.

\subsection{Menopause in FemTech industry}

In recent years, the boom of the FemTech (Female Technology) industry, which develops technological products and services for women's health, reached women in peri-menopause as intended 
consumers. So far, initiatives have been focusing on 'solving' the most prevalent and visible events in the climacteric, such as hot flushes. For example, the Grace bracelet ${ }^{1}$ was designed to detect hot flushes and cool down the wearer. Its marketing material frames hot flushes as 'embarrassing' and offers a 'solution' to reverse their effect. $\mathrm{Pebal}^{2}$ and Menopod ${ }^{3}$ are hand-held devices that can be pressed to become cold, and then applied on the body. Other companies, such as Lusomé and Cool-Jams, produce luxury garments and clothing for women with night sweats, which aim at keeping the wearer dry and cool. Mobile apps have been designed for selftracking of experienced changes. For example, based on a fixed list of 'symptoms', Hot Flash Sisters and Menopause View suggest the user to chart patterns to show to their doctor. MySysters and myPause correlate tracked 'symptoms' with data on the user's lifestyle to provide 'symptom management' advice. This approach to selftracking, while urging women to 'take control', yields the risk of reducing the menopausal experience to essentialised definitions [46], i.e. concluding that there is an innate, universal experience of menopause shared by all women -besides continuing to exclude people who go through menopause without being women, and are not even targeted as users. As warned by Homewood and by Lazar et al. [61], this not only medicalises menopause -as it replaces the richness of the lived experience with standard lists to be validated by medical practitioners- but may also further deepen stigma, especially for those who cannot find their experiences reflected in the predefined lists, and for those who self-blame for the 'behaviours' that supposedly trigger them.

\subsection{Menopause in $\mathrm{HCI}$}

Although several life events such as pregnancy [79, 92], breastfeeding $[6,50,106]$, and menstruation $[40,87,96]$ have received attention from HCI, menopause remained unexplored until very recently. The first works on menopause followed a rationale similar to that of commercial symptom trackers. Lee et al. [62] interviewed women in South Korea as a first step in the design of a mobile health application for menopause support. Similarly, Trujillo and colleagues [84, 94, 95] elicited requirements from women and other stakeholders for a mobile application that would coach users in developing "healthy behaviours" to reduce cardiovascular risk. With the goal of learning which 'symptoms' occur in clusters, Ismail et al. [53] ran a study where participants going through menopause had to map their experiences and how they were related, using an ad hoc iPad application.

Our work follows these early attempts of including people going through menopause in a design process, but we explicitly take a political stance by engaging with a women's health agenda [1]. We also build upon the work of Lazar et al. [61], who framed menopause as a social justice matter, as people are marginalised because of their gender and their age. Lazar et al. reported on their analysis of a US-based subreddit forum where women talked about their experiences with menopause. The authors conceptualised the lived experiences of menopause as social and argued that HCI is well

\footnotetext{
${ }^{1}$ www.gracecooling.com, last accessed August 5, 2020.

${ }^{2}$ https://www.cambridgeconsultants.com/press-releases/helping-women-takecontrol-menopausal-hot-flushes, last accessed August 5, 2020.

${ }^{3}$ https://menopod.com, last accessed August 5, 2020
}

positioned to address this aspect of the experience as it gets mediated more and more by sociotechnical systems. In particular, they identified an opportunity for HCI researchers to contribute in "accommodating bodily transformation", which closely resonates with our approach. In a second paper based on their forum analysis, the authors mapped a variety of "experience claims" about menopause to design propositions that HCI could drive [9]. They contributed with design frames and their corresponding critiques, inspired by several themes. The design frames were not offered to be taken as promising ways of designing for menopause in HCI, but as tools to reflect on tensions in women's health. We see our work aligned with one of Bardzell et al.'s themes, on the tension between giving importance to physiological experiences and reducing menopause to them. We recognise the entanglement between the physical and the psychosocial, and we reject mind/body duality, acknowledging menopausal experiences in a holistic way.

Tutia et al. [97] interviewed US-based women and ran a workshop with them, in which participants wrote a letter to their premenopause self and shared experiences of their climacteric. Based on insights around silence, lack of control, marginalisation, and responses to the absence of menstruation, the authors proposed three design provocations: a cooling bra for hot flushes; an interactive map to share people's stories about menopause; and an adaptive gatherings platform to facilitate social support. Like us, they do not see menopause as a problem needing a unique technological response, and instead, called designers to cater for experiences of menopause. Similar to [9], the authors remained critical of their own design provocations. Finally, Homewood [46] questioned the design of self-tracking tools for peri-menopause and decided to not design for this context, arguing that excessive body awareness has lead people to a desire of controlling the body via medical intervention. Importantly, we adhere to Homewood's critique, which pertains to technology that quantifies the body. However, it does not consider alternative approaches to technology and the body, such as the one enacted in our work. We argue that it is not the focus on the body during menopause what might be counter-productive, but the values with which the body is approached. Focusing on the body does not imply emphasising (nor reducing the experience to) illness or malfunction. For HCI, it can mean supporting people in becoming more aware of and getting to know their own body, discovering and attuning to pleasurable experiences (e.g., [83]), and coming to terms with not so comfortable ones. Although outside the context of menopause, we find particularly relevant design works on body knowledge through intimately looking and touching the body (e.g., $[2,20])$. We see promising opportunities for work in HCI that addresses unexplored paths, deeply engaging with the body.

\subsection{Soma Design}

Our work finds inspiration in soma design, which rejects the dichotomy between body and mind, and in consequence, the superior value of the mind over the rest of the body. Instead, soma design fosters a slow cultivation of attunement and appreciation for the soma as a unity including body, emotion, and movement. Soma design builds on philosopher Shusterman's somaesthetics theory -an ethical and aesthetic project with the aim of living " $a$ better life" by engaging with and learning from all our senses [85]. In 
HCI, somaesthetics has been used as a theoretical framework for experience-centred approaches to interaction (e.g., $[63,105])$ that go beyond merely instrumental use of technology. Authors such as Höök, Khut, Loke, Schiphorst, and their colleagues [48, 59, 70, 82] have applied somaesthetics in interaction design under the umbrella term of soma design. Pragmatically, a soma design process has the body as a starting point and leverages on the aesthetics afforded by sociodigital materials and the act of shaping them into orchestrated experiences [48]. In our work, we recognise the soma as experiential, shaped by sociocultural and political environments [49], and we see somatic practices as framing ethical relationships between caring for oneself and caring for the world [70]. We are particularly inspired by soma design in its encouragement of design processes that are slow, thoughtful, and harmonising with the human condition [48]. In the rest of this paper, when we use the term body within our work, we conceptualise it as a soma, unless we explicitly refer to a concrete aspect of it, such as its visual appearance.

\section{RESEARCH POSITIONALITY AND METHODS}

Our research takes place in Sweden, and our team is composed of women (ages 29-38) from European and South American countries. None of the authors has gone through menopause yet but some have experienced certain common aspects of it, such as irregular menstrual cycles, prolonged absence of menstruation, or anxiety and depressive feelings.

When planning to design with people going through menopause, we were faced with challenges related to opening up conversations about this meaningful, intimate topic still often surrounded by silence. We identified the need of creating partnerships with them that are slowly cultivated [13] and based on mutual trust and respect. To start partnering with people in our local area, we realised that we needed to hear their stories one by one and in depth, instead of directly jumping to a quick, hectic, often impersonal workshop. We designed a flyer inviting people who had experienced "signs of menopause" to participate in the research. As a political stance towards inclusivity and diversity, we did not specify gender or age range, and we produced an English and a Swedish version of the flyer. The call specified that participation would consist of an interview and a potential invitation to a design workshop; that it would not involve any medical treatment nor medication; and that cinema tickets would be offered as a gift. We distributed the flyer through the first author's extended social circles, posted it on local Facebook groups about menstruation and menopause, as well as groups for expats based in Sweden. Twenty people filled in the screening survey linked on the flyer, from which we selected an initial set of 12 , based on diversity in age, countries of origin, languages, relationship status, time since they last menstruated (if they did menstruate), and type of menopause if relevant (induced or not). In the following sections, we report on the interviews and the design workshop.

\section{INTERVIEWS: UNDERSTANDING LIVED EXPERIENCES OF MENOPAUSE}

We were interested in listening to participants' stories about their transition to menopause, including any changes that they noticed and how they experienced and reacted to them if at all. The first author interviewed twelve women (aged 44-58), who considered themselves to be from one or more countries, including Argentina, Finland, France, and Sweden. All twelve were in the workforce at the moment of the interview (summer of 2019 in the Northern hemisphere). Two participants were divorced, two were in a relationship, and eight were married or in a domestic partnership. All participants had experiences of motherhood and were heterosexual. Half of the participants had menstruated in the last year, five had stopped in the last 1-6 years, and one 10 years ago. One participant had had an induced menopause. Table 1 summarises these demographics. To further ensure anonymity, we report on education level and socioeconomic class in an aggregated way. Two participants had completed high-school, and ten had a University degree. They self-identified as currently belonging to the working class (2/12), middle class (5/12), and upper-middle class (5/12).

The interview protocol was semi-structured. The interviewer deliberately avoided listing changes and mentioning the term 'symptom'. Instead, she started by asking: "Could you tell me about when you started experiencing menopause?" and "Do you feel differently or the same as before?". She paid attention to stories depicting concrete experiences of menopause and strategies to live with them, including which objects, services, devices, or habits supported them. The relationship with media, health institutions, and society during the climacteric was also covered. Other questions included: "How did you experience these changes?"; "How did you feel in your body during these changes? And now?"; "Does anybody know you're going through menopause?"; "Is there something you would have liked to know about menopause before experiencing it?"; "What has been the worst part of your menopause experience? And the best?".

Participants chose when and where to have the interview and in which language, as long as it was spoken by the interviewer. Interviews lasted between half an hour and two hours, and were conducted in participants' homes or workplace, or at our institution. Participants were told they could use words in their native languages if they could not find the term in English. The first author obtained written informed consent at the beginning of each session. She then transcribed the audio recorded interviews while anonymising them (participants either picked or let us pick their pseudonyms), and translated all the non-English content, keeping some terms in the original language to preserve linguistic nuances.

\section{ANALYSIS: STRATEGIES TO LIVE WITH EXPERIENCES OF MENOPAUSE}

We conducted an inductive thematic analysis [19] across the full interview data set. The Western cultural context of the research and our lived experiences of our bodies influenced our questions and what we found interesting when analysing the data. All authors got familiar with the transcripts, generating initial codes and discussing the most salient. We then constructed themes that articulate how participants talk about their bodily-rooted yet socially-shaped experiences of menopause, around current practices to live with them.

The body -how it feels, how it looks, how it changes- was a central part in their stories. Most defined their experiences of menopause through a combination of changes centred in the body, 


\begin{tabular}{|c|c|c|c|c|c|}
\hline Pseudonym & Age range & $\begin{array}{l}\text { Years since last } \\
\text { menstruation }\end{array}$ & $\begin{array}{l}\text { Country(ies) } \\
\text { of origin }\end{array}$ & Relationship status & $\begin{array}{l}\text { Interview } \\
\text { language }\end{array}$ \\
\hline Thilde & $30-44$ & 0 & Sweden & Married/Domestic partnership & English \\
\hline Edith & $46-55$ & 0 & Argentina & Married/Domestic partnership & Spanish \\
\hline Bea & $46-55$ & 0 & Sweden & Divorced & English \\
\hline Amanda & $46-55$ & 0 & Argentina & Relationship & Spanish \\
\hline Anna & $46-55$ & 0 & Sweden & Married/Domestic partnership & English \\
\hline Mona & $46-55$ & 0 & Argentina & Married/Domestic partnership & Spanish \\
\hline Helen & $46-55$ & $1-6$ & Finland & Married/Domestic partnership & English \\
\hline Alicia & $46-55$ & $1-6$ & $\begin{array}{l}\text { Argentina } \\
\text { and Sweden }\end{array}$ & Relationship & Spanish \\
\hline Kerstin & $46-55$ & $1-6$ & Sweden & Married/Domestic partnership & English \\
\hline Argenta & $56-65$ & 1-6 (induced) & Argentina & Married/Domestic partnership & Spanish \\
\hline Charlotte & $56-65$ & $1-6$ & France & Married/Domestic partnership & English \\
\hline Ava & $56-65$ & $6+$ & Sweden & Divorced & English \\
\hline
\end{tabular}

Table 1: Interviewees' demographics as of August 2019 and main language for each interview.

lived within the context of interpersonal relationships. These changes include pain, weight gain, sleep disturbances, hot flushes, mood swings, feelings of anxiety, sadness, angst, anguish, increase/decrease of libido and of energy levels, renewed sense of confidence and freedom, etc. Participants described their experiences interweaving emotions, physical sensations and other people's perceptions, rather than highlighting a specific body part in isolation as commonly reported in the biomedical literature. Noticing and trying to make sense of a variety of changes, and developing strategies to live with and as a changing body, are the most prominent aspects of the data. We present our results around such (often intersecting) strategies.

\subsection{Noticing and understanding the body}

We were surprised that eight participants shared evocative descriptions of noticing feelings of, in their own words: anguish, angst, anxiety, depression, irritation, mood swings, and sadness, as experienced through the whole body, not just the mind, and deeply intertwined with the context in which the body lives. For example, Thilde described: "I feel it sort of in my stomach, in my chest area I would say (...) I get fidgety, sort of, I feel I have to do something and also when I get irritated, I become irritated so fast and I have no patience at all, it happens and it's almost like... in my whole body I experience it". Five participants named these feelings as the worst part of their menopausal experience. Alicia, for example, emphasised the primacy of "anguish" in her transition: "It's the anguish, if I could tell you something about menopause that got me personally... It has been those ups and downs of mood (...), suddenly I'm very excited and very happy and suddenly I can go down into a... not depression, but anguish, I don't know if anguish, how to tell you? A sadness". When probed about this feeling, she elaborated: "It's a hormonal anguish that one doesn't know why (...) This anguish that suddenly grabbed me, with my partner, with my children...” (Alicia). In a similar way, Kerstin made sense of her experience by conceptualising it as "bodily anxiety" and "not really anxiety" that originates in separate life factors.
For several participants, these strong negative feelings were inseparable from experiences such as hot flushes or headaches, traditionally portrayed in physiological terms by medical literature. For example, Thilde hypothesised that "getting more irritable" worsened her headaches. Kerstin talked about anxiety and hot flushes interchangeably, as in this fragment: "The problem is when they come right when you're about to fall asleep and they do (...) and they wake me up because it's like an anxiety attack, very much like... It starts without being hot, or sweat, or anything, it starts with this sense of 'uncomfortable, something is uncomfortable'. (...) What's going on? And I really have to stop myself from thinking there's something wrong at work or (...) in my marriage or (...) with the kids, and this is why I have this anxiety attack now, and then I'm like 'nooo, Kerstin, this is menopause'. And then it comes the wave, the heat wave" (Kerstin).

Participants told us several stories where a set of changes, especially during the months leading to menopause, made them pay more attention to their body and to the patterns behind such changes. For example, Edith noticed the increasing frequency of hot flushes at night. Still, noticing what was different in the body required having the time to do so. Some, like Argenta, explained that she had not noticed some experiences earlier, such as hot flushes, because "she worked so much" opening her new company. For others, such as Kerstin and Mona, noticing the changes was a long process, deeply entangled with trying to make sense of them. They were able to notice menopause experiences in retrospective, once they understood that certain events -such as sleep disturbanceswere indeed related it. Some participants described noticing experiences of menopause through the perception of others, in particular their family members and co-workers, which contributes to show how these experiences are socially shaped. Edith first noticed her swollen abdomen after a comment from her husband: "That, I started to realise now when I went on vacation, because my husband told me 'you are super bloated in the stomach, what is happening?' ". Thilde made sense of her own hot flushes after seeing other women her age: "The first time it happened I didn't understand what it was. Then I understood what it was [Laughs] during a meeting at work because I work mainly with women, and everyone around 50 wanted to open 
the window all the time and fanning themselves with a magazine or books. Oh, now I know what it is". Similarly, Kerstin found patterns in women's experiences by reading posts in a Facebook group about menopause, which helped her recognise her increased hip and feet pain as probably related with menopause. Sometimes, participants even identified their own mood swings through the gaze of others, feeling a disconnection between their perceivable behaviour and their real state: "I notice the mood swings because my daughter tells me 'mum why are you so angry about such a thing?' (...) And I'm not so angry, but she realised" (Edith). Similarly, Alicia explained: "I realise that sometimes I have those heat rises suddenly, right? Because my daughter or anyone tells me: 'mum, it's cold', and I'm hot. I lower the car window and everyone is freezing" [Laughs]. Participants also attributed importance to certain experiences according to their visibility: Being seen sweating was for Charlotte, Helen and Bea the biggest problem with hot flushes. Bea said: "I just feel embarrassed sometimes when there's people around me (...) because I'm getting red in my face like blushing".

Participants' accounts highlight that, although counting with years of valuable body knowledge, understanding the changes is also often a continuous process and requires work. Kerstin explained a need of (re)learning from and getting to 'own' her body again: "It's a body that isn't mine yet, I'm still trying to get used to it so because I gained weight, there's this thing here [Touches her belly and laughs]. And I've always been, you know, going to the gym quite a lot, and this thing is in the way! (...) My body is no longer following the patterns, and the shape, my body awareness, the way it used to be, so I have to learn what it is" (Kerstin). In contrast, Anna fantasised with the idea of removing her ovaries and uterus if that made the negative side of her menopausal experience disappear: "I' $m$ trying to see it as a part of my life that I'm going through... that I want it to go away. Sometimes I think it's best to take away the things from the body, but that's not a solution (...). Take away my ovaries and my... (...) I thought, when taking away the things, it will disappear from my body (...), all the feelings will disappear, and I will get normal again" (Anna).

Our data contains examples from all the participants being uncertain on whether their experiences were triggered by their menopause transition or just happened around the same time. For example, Mona summarised: "The worst is the uncertainty. The change of the body, at the beginning, I mean, to me it was like: 'I don't understand'. (...) I didn't know what was happening: Is it that I'm sick? Is there something wrong with me?" (Mona). Participants' uncertainty came from two main sources: Lack of preparation for menopause (including issues of access to clear, trustworthy information [26], intergenerational silence and societal taboos [37]); and unpredictability of bodily changes $[23,61]$. Regarding lack of preparation, participants said that they would have liked to know in advance what type of experiences they could expect, especially if related to depression (Argenta, Alicia, Thilde). Lack of preparation motivated participants to take action by themselves once they understood their own lived experience. For example, by passing their wisdom and even teaching co-workers, children, and younger friends. Kerstin, for example, openly talks about menopause whenever she has a hot flush in public: "I tell everyone and I think it's part of my obligation (...) Because I want to remove the taboo".
In summary, this theme captures participants' accounts regarding feelings of anguish and irritation as experienced in the whole body (not just the mind) and inseparable from other life factors, in contrast with the typical portrayal in biomedical literature. Changes during peri-menopause made participants pay more attention to their body, but this 'noticing' was a long, continuous process often marked by uncertainty, where some experiences were understood and acknowledged in retrospective and sometimes through the gaze of others.

\subsection{Trusting, accepting and appreciating the body}

In some cases, cultivating attention of their body through the years led participants to trust their own lived experience over some doctors' arbitrary perceptions. For example, Thilde prioritised knowledge of her own body when experiencing signs of menopause: "Everyone who has a vagina knows that you can feel different things and you can feel almost instinctively this is not the way it's supposed to feel because you had it all your life (...) and you go to a male gynaecologist and he says 'no, everything's fine', but it isn't, I can feel it's not, 'oh but it is, I can't find anything that is wrong' "' (Thilde). Similarly, Ava trusted herself when a doctor dismissed her intuition about menopause, telling her "you're too young for that" (she was indeed in peri-menopause).

Noticing a variety of changes, understanding them, trusting the body, and realising that in many cases they cannot be 'controlled', lead some participants to become more accepting of themselves, and to reflect on the importance of this acceptance for having a better life. For example, Mona used a humorous metaphor to describe the moment she noticed her "shape" had changed. This realisation seems to have initiated her in a journey to acceptance: "What I say is that I became a pizza bun. [Laughs] (...) Suddenly I started to have a belly, the body all flabby (...). After a while I found that definition, in fact, I was making pizza, and when I was preparing the bun: That's how my body is now! [Laughs] It turned into a pizza bun, and it's like I realised that no matter what I do, my body is like that now" [Laughs] (Mona). Kerstin reflected upon the cyclical nature of her night hot flushes, concluding they will continue coming regardless of her trying to "dissolve" or "resist" them. She explained that her "strategy" is to accept, rather than fight the "bodily anxiety", which requires work from her side to "let it rest, let it flow through". Thilde hoped that acceptance of menopause, as an act of resistance against fear, would make her transition easier: "Because if I resent everything, and was scared of aging and everything I think it would be harder. (...) I think by accepting menopause it will be easier for me to live an active life (...) You know, a life that is a good life" (Thilde). Importantly, this acceptance was for Thilde not a passive attitude but a wilful action: "I think it will be easier if I [say]: Well, now menopause is here, what can I do about it? Or how should I handle it? What do I have to do to function, (...) to feel good?". For some participants, making the effort of accepting the existence of uncomfortable experiences, rather than denying them, was part of resisting the medicalisation of menopause and the normative societal view that "makes you invisible" (Argenta). For example, Kerstin reflected on her worsened hip pain: "What I'm struggling with is this: I don't want to medicate 
against menopause, I want to live this and I want to transform with this, and I want to be accepting, but the pain... is hard".

Paying attention to the body and making sense not just of the changes but also of what remained unchanged imbued participants with a renewed curiosity and appreciation for their bodies, and was an opportunity to be grateful for the positive aspects. For example, Bea said: "I went to the funeral of a friend yesterday (...) I'm still glad I'm alive and functioning”. Similarly, Thilde reflected about the human body: "I think it's actually amazing that any human body, whatever malfunction they have, can work at all". Kerstin recognised herself as "also slightly more accepting of my own body (...). I don't mean the pain but my body shape". For Thilde, reading about menopause allowed her to have more compassion for herself and for others. She reflected on how others should not be dismissive of anyone's experiences: "I learnt that many many women have gone through early menopause such as 25 years old and so on so that has helped me to understand that it's something that happens when people are quite young and I always think about that sentence, 'everyone is fighting a battle you know nothing about, so be kind always'. (...) I hate people who say, because someone is being a bitch, 'oh it's menopause, or PMS, yeah it could be, but it could also be something else you know nothing about" (Thilde).

This theme highlights how paying attention to their body along the years leading to menopause built participants' trust in their own lived experience, which sometimes contradicted their doctor's assumptions. Understanding and trusting their body seems to have made self-acceptance easier. In some cases, this acceptance came with a resistance to a medicalised view of menopause, and a feeling of compassion for themselves and for others.

\subsection{Engaging with wellbeing holistically}

Participants engaged in bodily practices with a variety of goals: coping with their mood swings or anxiety, losing weight, alleviating pain, grounding themselves in the present, disconnecting from overstimulating technology, socialising, and more generally feeling healthy. These practices include yoga, meditation, Pilates, reiki, massage, sauna, walking, running, and a remarkable variety of gym routines and sports. Alicia, for example, practices yoga and meditation as they help her "find calm within myself", in order to deal with irritation and lack of patience and avoid over-thinking. In particular, Alicia referred to these practices as aiding her to be on top of her anguish: "In very stressful periods it has helped me to control myself when that anguish comes to me". She described and enacted her daily routine: "Sometimes I can't do 20 minutes every morning so what I do is, for about 5 minutes, this thing of 'being here, now', you know? Putting my feet on the floor: 'I'm here, now', and breathing and closing my eyes" (Alicia). Bodily activities were a way for some participants to connect with their co-workers, friends, or for meeting new people. For example, Alicia and her co-workers often have walking meetings and use self-tracking to compare how many steps they walk per day.

Participants had also been developing bodily strategies to address certain experiences that emerged or increased with menopause. For example, Thilde has suffered from strong headaches throughout life. Although they got worse with menopause, she has "better coping techniques now that I'm older". She described how she gets help from her husband to press the muscles to increase blood flow: "When I start to get my migraines, my husband has learnt what muscles to press and how to press them and I can also feel if it's hard enough and it has to be really... He doesn't press it, he squeezes it between his fingers, and when I feel a bit better, then he squeezes harder" (Thilde). For Kerstin, "pain is very hard and it feels like it's reducing the quality of my life". She makes a conscious effort to "walk normal", to prevent her hip and feet problems to get worse, even if this means more discomfort in the short term. Edith uses objects in the home to engage with the body after doing sports, including electrodes for muscle stimulation, gadgets for manual massage, a roll to stretch her back, a rope to jump, etc. She shared thoughts about her strategy of complementing exercise with products in close contact with the skin, making "the whole body" feel better: "It has a lot to do with gymnastics, physical movement, using creams, things to feel better. Sometimes I say to my husband: It's weird but you put something here [on the neck] and you feel 'ah, now the whole problem is solved', the whole body feels fantastic" [Laughs] (Edith).

Besides engaging more with bodily practices, participants mentioned a variety of lifestyle changes. These include drinking more water, eating healthier food, consuming less alcohol (or more in special occasions), taking vitamins, etc. Edith, in particular, makes use of indigenous recipes from her region in Argentina, such as unguents, and mixes of dry herbs for tea, to aid the good functioning of stomach and liver, and to relieve pain in muscles and joints. Following the advice of her nutritionist in Sweden, she decided to start collecting red clover [18] from the local forest, a plant that has been traditionally used to address hot flushes, vaginal dryness and skin ageing.

Accounts of this strategy configure a holistic view of wellbeing that does not always address specific struggles related to menopause as much as participants' global health: to be calmer, to live longer. For example, Alicia talked about losing weight "not because of an aesthetic issue", but as "a matter of feeling good, of feeling one can climb the stairs (...). It is a health issue, is to avoid diabetes, is to avoid cholesterol, is to live longer". Similarly, Amanda talked about not needing aesthetic treatments or surgeries to feel good during menopause, and said instead that "perhaps one can do things that one likes, hobbies, trying to better manage the spiritual, the physical, the emotional, as a general connection".

In summary, this theme captures how and why participants engaged with bodily practices and lifestyle changes, addressing their wellbeing from a holistic perspective that avoids a duality between body and mind, and between the individual and the social.

\subsection{Making space for a new me}

The appearance of often unpredictable, uncontrollable changes seems to have allowed participants to take a step further and actually make space for a new self. Curiously, Kerstin found the experience of hot flushes as redefining part of her personhood: "I've been a cold person all my life, I don't have to be cold anymore and it's weird and I realise how much I have associated my own person with this (...). I would be the one in the morning saying 'I' $m$ worrying about this, I'm going to put an extra layer', and now I'm: 'Oh, I can just wait for a hot flush!' It's so good!' [Laughs] (Kerstin). 
Living uncomfortable experiences opened opportunities for participants to grow as a person in a holistic way. Like in previous themes, this did not come without effort. Amanda talked about constantly "working" with her character and resorting to humour to be able to laugh about her mood swings. Alicia noticed "a change in me as a person" and expressed feeling more confident and calmer, but to reach this point, she first needed to accept the changes: "It's as if life indirectly told you 'well, here you are, now you have to rethink your life' (...) So you have to befriend those changes, I don't want to be enemies with them, so I have to find a way to improve my quality of life" (Alicia). Importantly, this acceptance was not a passive attitude but an active stance: "I'm learning to know myself better (...). So my way has been to know better what I can do to be OK with myself" (Alicia). In a similar vein, Kerstin reflected about change throughout life and the hard process of "turning into a butterfly": "You go through a big transition when you start menstruating and then (...) when you have children, on every level, bodily and personality and what not, and I've gone through big changes (...). And now I'm going through another one, and I feel like this is a richness in life and I look upon crisis as what the word means, they mean change, and that change is painful, and so menopause is a painful change but it's also this opportunity, it's like pain and opportunity combined (...). I see a key translating it into a positive possibility and sometimes that's hard work, but I feel my inner way of thinking about it is: I'm a caterpillar turning into a butterfly and there's some pain involved in the [process]" (Kerstin). However, she clarified that for her, the construction of the self is a continuous process along life, and resisted the view of menopause as the ultimate chance to (re)define oneself: "I'm also not going to romanticise stuff like 'oh we're now finally at the age in which we can be ourselves' (...) I believe I can change and I also change with my hormonal levels and I've always done so, and I know my personality is not a given, is something I work with" (Kerstin).

We found several examples where the climacteric was a trigger for participants to start making space for self-care. Still, this decision did not come easy to some, because they had always accommodated the needs of their family first: "It's much more important for me to have fun and to do things and not wait for tomorrow and just do what I want to do myself and not what others want to do. (...) It wasn't easy. It's a long way to come to that decision" (Ava). Alicia also expressed this with certain guilt: "I think it will sound very selfish, but now I think about myself, a lot, about my needs"; and Anna found a new sense of determination: "It's important for me to do things that I always wanted to do and now I really take time to do that (...) The best part [of menopause] is that I know what I want (...) I've become tougher".

Some participants decided to prioritise resting, as well as favouring activities that do not involve watching a screen or being socially reachable. Among others, Thilde felt in need of " $a$ way of distancing myself from technology" to increase her life quality, and recognised the importance of allowing herself to rest: "Now I need more time to relax. So I leave dishes, and lie down and read for an hour instead because I feel I really, really need it, to not break down" (Thilde).

Making space for a new self was often a strategy developed in relation to others -either as a consequence of societal pressure or of actively resisting it. For example, Argenta defied the "invisibility" that comes with age- and gender-based marginalisation: "The thing is that here in Sweden and in the world (...) there's like a denial of the capabilities of people beyond 50 (...) They make you invisible and I refuse (...) For me it's like a challenge not to accept it. (...) I don't accept being discriminated for being a woman and for being old" (Argenta). Finally, socialisation needs and ways of being social are another salient change in this theme. Some women had been wanting to socialise less with their regular acquaintances, because this "drains" their energy (Thilde) or because they did not enjoy it as they did before (Kerstin, Argenta).

This theme shows how the changes brought by the climacteric inspired participants to make space for a new self, growing as a person holistically, prioritising self-care (sometimes for the first time in their lives and in some cases, with feelings of guilt), and redefining socialisation habits. This making space, still, required effort, time, and actively seeking to accept oneself.

\section{WORKSHOP: DESIGNING WITH LIVED EXPERIENCES OF MENOPAUSE}

After the interviews, we organised a design workshop with a smaller number of participants. Inspired by soma design, we wanted the activities to start slowly and gently engaging with the body. We invited Sofie, a professional Feldenkrais practitioner, to give an Awareness Through Movement (ATM) lesson inspired by the experiences that participants had shared with us. An ATM lesson is a group class in the Feldenkrais method of somatic education [38], which promotes self-awareness with the goal of increasing sensitivity to movement. Through playful experimentation, it invites to slow down movement and attune to how body parts are connected. The Feldenkrais method offers a framework for being attentive to how the body exists in the world, allowing one to detect fine details of movement that previously went unnoticed. For example, a typical Feldenkrais activity is slow walking while paying attention to the spine, shoulders, and hips as they move together. The goal of an ATM lesson, in particular, is for people to become aware of learned movement patterns in order to widen one's repertoire and find pleasure in alternative, often subtle ways of performing habitual movements. We are not interested in the effectiveness of the Feldenkrais method to generate 'healthier' movements from a medical point of view. Instead, we chose this non-harmful practice because we find it inspiring and effective in making us pay attention to our bodies, and because it has been successfully used in design processes in the past (e.g., [14, 67, 69, 88, 91, 93]).

In the frame of cultivating partnerships, we wished to keep the group small enough to create a safe, intimate space for sharing while leveraging on social interaction. We only contacted six out of the twelve interviewees, trying to ensure a diversity of experiences. Based on their availability, we scheduled a session with two of them, plus a third participant that heard about our research and was interested in joining. Three women (aged 49-55) participated in the workshop: Anna and Kerstin from the interview study, and Miriam. In that moment (early winter 2020) Anna worked as a digital developer in the education sector, Kerstin held an academic position in Interaction Design, and Miriam was trained as a digital business strategist and worked as a consultant.

Prior to the workshop, we sent the proposed schedule and the consent form to the participants, and collected their dietary restrictions and preferences. The day of the workshop, the first and second 

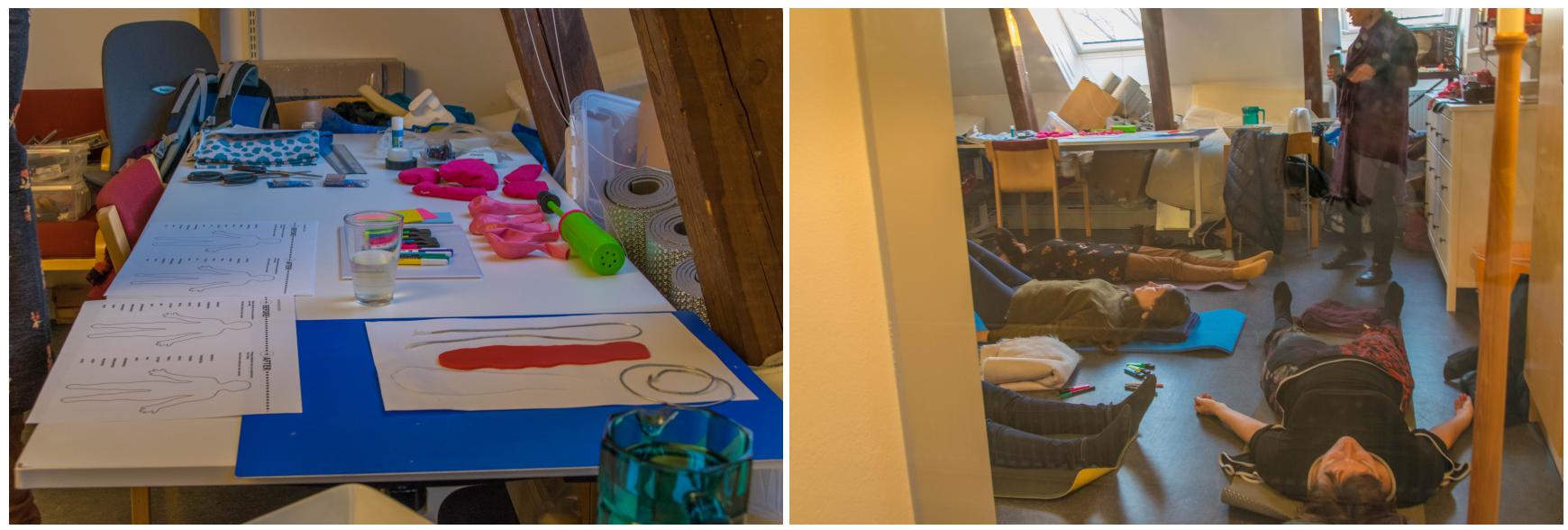

Figure 1: Workshop activities: Design materials provided for prototyping (left). Participants engaging in an ATM lesson (right).

author welcomed participants in a relaxing space at our design lab. It was important for us that they had time to introduce themselves, talk, and feel comfortable in the setting. For each activity, we minimised the number of researchers present in order to invite sharing and reflection. During breakfast, Sofie further introduced the Feldenkrais method, and we obtained written consent. Then, the first author, the three participants and Sofie moved to a quiet room in our lab. The room contained yoga mats, blankets, chairs, lamps for cosy lighting, a whiteboard, and a table with design materials (Fig. 1 left). Acknowledging that the materials would indeed influence what participants could design, we chose materials that would allow them to prototype experiences engaging a variety of senses, as well as wearable and shape-changing designs, since we were interested in designing with and for the body. Materials included paper-prototyping supplies, sewing materials and tools, materials relevant for prototyping shape-changing structures (balloons, wire), and for exploring changes in temperature and tactile sensations (a kettle, a hairdryer, water, empty and gallium-filled silicone tubes -a non toxic element with interesting physical properties, as it melts at 29 degrees-, heat pads, vibrator motors). Participants also had access to paper and pens to sketch their ideas.

To draw attention to their current lived body, the participants and the first author filled in a body map [68], a sheet of paper with a pre-printed body silhouette that can be sketched upon and annotated, often used in soma design. In our design practice, body maps have helped us and participants to make the time and space to reflect on being in our body. Crucially, they have allowed us to externalise the differences in body awareness before and after a Feldenkrais lesson, to then start design explorations. In addition, sharing their content has encouraged us to refine our vocabulary to describe bodily experiences, and has contributed to build trust and comfort within the group. Sofie then led a 45-minute ATM session inspired by the movements made by babies when rolling on the floor, implicitly emphasising the movements of the sternum bone and the chest area when breathing, as sites that we tend to protect when in distress and to open when feeling brave and adventurous (Fig. 1 right). At the end of the lesson, the participants and the first author filled in a second body map, and shared their reflections in turns. The ATM session was followed by a break and a discussion between participants facilitated by the first author. We were interested in how they related what they felt during the lesson, with their experiences of menopause, to then identify specific experiences, desires, or concerns that could be explored through design. Once the group collectively choose a set of experiential qualities to design for, the first author introduced the available materials. The second author joined the session to help facilitating the prototyping and the filming of design ideas. We purposely avoided moderating the activity too rigidly, and let participants set the pace instead, which resulted in a deep, slow, and yet playful body-storming. Participants spontaneously 'interviewed' each other and collaboratively built upon each other's ideas. After a lunch break, participants continued designing, enacting their ideas, and filming the most promising ones. Finally, the session was wrapped up by reflecting upon the design concepts and the overall experience. We used the body maps, sketches of design ideas, physical prototypes and their explanatory videos, our written notes, and the filmed discussions, in order to reflect on the design process and on the final design concepts, which we report in the next section.

\subsection{Participants' design concepts: The cocoon and the spike mat}

During the discussion where participants linked the Feldenkrais lesson with their climacteric, they shared a rich variety of experiences that reflect our findings from the interviews. Participants collectively decided to design with bodily anxiety, introversion, and what we could call sleep is gold. Kerstin commented that she wanted to "allow for more introversion" in her life and explained: "I don't want to become an extrovert. I don't want to deal with the anxiety in the sense of getting rid of it: it's the way it is. I just want space. And my space is my bed. How can I find a space that I can go into? Is there a way to have my bed, my safe, my closed space, during the day... or somewhere else? Make my energy go to the inside. Like a shell" (Kerstin). Miriam compared this with experiences of "burnout", when she "did not want to do much". Anna was interested in designing for sleep, and all participants agreed in that "sleep is gold". She emphasised the experience of waking up at night with pain 

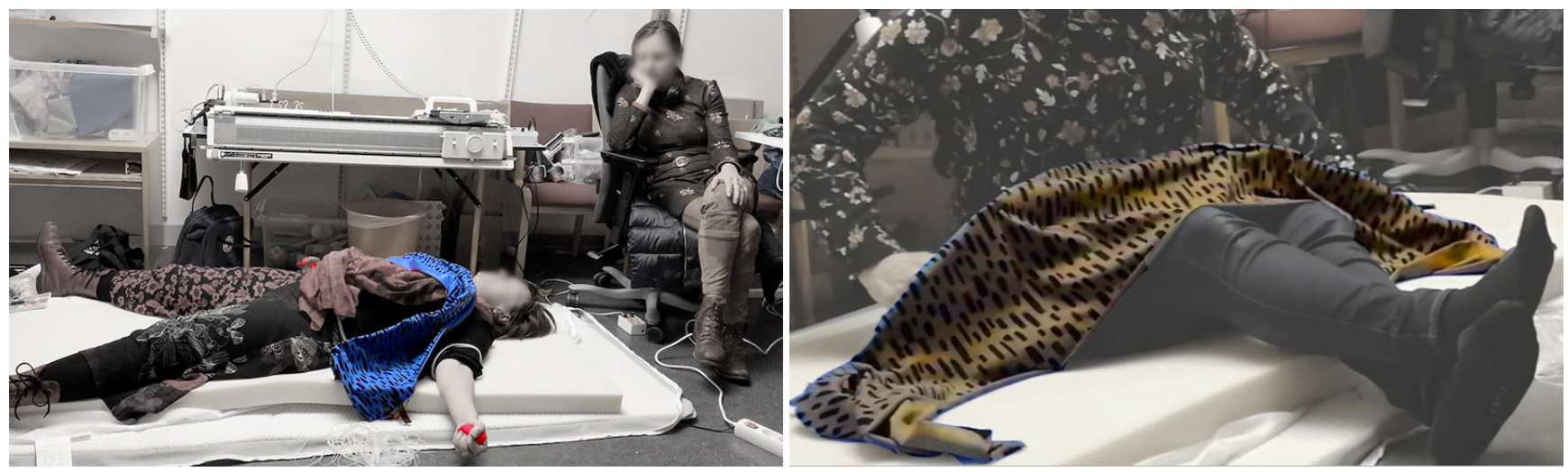

Figure 2: Design concepts: Kerstin wears the cocoon (in blue), pumping the water up, while Miriam narrates the breathing guidance (left). Anna wraps the spike mat (in orange) around her legs. The actuators would massage her muscles while she sleeps (right).

in her muscles, which lead her to ideate designs to be used in bed. Next, we present the two concepts that participants proposed as a response to these experiences: the cocoon, and the spike mat.

From the Feldenkrais lesson, participants got inspired by movements of contraction and release, which they compared to childbirth and to orgasm. They found these paired movements relevant and evocative in the context of bodily anxiety. Kerstin and Anna mentioned needing to stretch in bed and take space when they get night hot flushes. Miriam was interested in using contraction and release within breathing techniques, in order to accept and 'ride' the heat waves: "Is there a way to surf the wave? What if I go into my mind and say: 'OK, this is the magical heat from Mother Earth, from the sun, coming to me through my blood, in this new age, it's my entering to this new age and I welcome you, just clean me... or, whatever you want to say... I'm yours, I'm getting ready to receive you, let's ride together'. What would happen then?" (Miriam). Participants combined these ideas by imagining a "cocoon" that, when in bed, would constrain them while allowing to push it. They also considered a "mini version" of the cocoon that could also be used when travelling. They envisioned it as a wearable that could be wrapped around oneself and that "has the same rhythm, the same pattern" (Kerstin) as their body movement, helping them breathe through a recorded audio guidance. Kerstin speculated with wrapping it around her head, reflecting her need for introversion, or around her torso or feet.

Inspired by the available materials, participants then imagined the cocoon as containing knitted or woven tubings filled with gallium. When the cocoon detected a hot flush, it would activate a Peltier element (a square-shaped metal module that produces heat on one side and cold on the other) to quickly make the tubings cold. This would, in turn, solidify the gallium, and the structure would become rigid, holding the wearer. They also incorporated an air flow to their design concept, which would be "touching your skin very softly" (Kerstin). Alternatively, they thought about using a series of distributed Peltier elements activated in sequence to generate a sense of breeze.

To prototype the cocoon, participants used wire to represent the gallium-filled tubings when solid, as we only had a few samples.
They attached the wire to a stretchable fabric and produced a semirigid structure. They imagined the cocoon "hugging" the body (Miriam), but leaving the arms relaxed. Optionally, the wearer could use headphones, and an audio recording would provide the breathing guidance. Upon activation, a gentle breeze would cool down the body, "keeping the same tempo as the breathing" (Kerstin). Participants also imagined using the silicone tubings with cold water instead of gallium. The water would have to be somehow pumped "in the direction of the heat" (Kerstin) or following a certain breathing pattern that intends to calm down the wearer. They discussed how to pump the water: With a hand pump? By using the feet instead? By making a certain stretching movement? They all agreed in that the movement should "harmonise with your breathing" (Kerstin), subtle enough for them to perform it while being half asleep; and that the system should be as quiet as possible to avoid waking up their partners. They prototyped a hand pump using a balloon attached to the cocoon via a tubing. Finally, they enacted and narrated the concept on camera (Fig. 2 left).

The conceptual idea behind the cocoon highlights the pairing of contraction and release, two opposite yet co-existing intentions in participants' lives: When contracting inside the cocoon, participants allow themselves to be introverts. When releasing and stretching out, they are making space -even if this space might still not be completely free but negotiated with others, such as partners. When we asked about what it is required to create a space for introversion, Kerstin quickly replied: "permission", and participants reflected about giving permission to themselves to be introverts. They talked about hotel rooms, cars, and their bikes as "perfect" spaces that allow them to spend time alone without having to meet others' expectations (Miriam). Spaces where "you don't need to be polite" (Miriam) and where it is possible "to work with myself" (Anna). The home was not seen by participants as a sufficiently free space since "there's always some expectation for you to take care of something" (Miriam), when instead, in menopause "we want to reclaim our space". Participants then speculated with having a space at work to be an introvert. These reflections clearly resonate with the Making space for a new me strategy from our interview analysis: Self-permission is still needed to break with gendered roles that 
traditionally framed women as care givers, and menopause comes as an opportunity to reclaim new roles and spaces. The design of the cocoon illustrates how design might approach the making space strategy by engaging with wellbeing holistically, specifically by making the body, as a soma, both the trigger and the site of the interaction.

Similar to our findings from the interviews, participants agreed in that "sleep is gold", as they had experiences of waking up several times per night, either feeling bodily anxiety, joint and muscle pain, or a combination. In parallel to the construction of the cocoon, Anna imagined a mat covered with sensors-actuators that, when activated, get perceived as "spikes" that massage the muscles. The system would detect when the wearer is uncomfortably moving in bed at night, or when the muscles are getting stiff. Then, it would trigger the actuators in a certain rhythm along the place of the body where the wearer has wrapped the mat. Additionally, the system should be capable of identifying the wearer's sleep stage, in order to regulate its intensity and lower the risk of waking them up. Participants used stretchable fabric to try on their own how the spike mat would feel if wrapped around the feet, the legs, the arms, etc. (Fig. 2 right). A key aspect behind this concept is that participants knew that they would probably continue waking up at night, and that they were not going to 'solve' the pain as a source of their negative experience. Instead, the spike mat would allow the wearer to get pleasurable sensations on the skin and muscles, and appreciate moments of calm that help them sleep better. The spike mat, then, is not designed for noticing the experience of sleep disturbances and keep track of how often it happens: it is for people who already noticed, and simply want to sleep.

\section{DISCUSSION}

"Little p politics (...) is about the micro-politics of everyday life. It is about the minute-by-minute choices and decisions that make us who we are. It is about desire and fear; how we construct them and how they construct us. It is about the politics of identity and place. (...) Little p politics is about taking seriously the feminist perspective that the personal is the political" [55]. Participants' stories illustrate how engaging with the little p politics of the body in the menopause transition constitutes an enactment of social justice in everyday life -for example, Edith preparing her own indigenous recipes for comprehensive health, and Ava deciding to prioritise her own moments of fun. We argue that it is once people notice and understand their own body, that they can share the experience with others, taking a step further towards fighting for societal change -as when Kerstin started to openly tell colleagues and students whenever she was having hot flushes at work; and when Thilde's self-compassion fueled compassion for others. Moreover, we can see their participation in this research as an active stance towards opening conversations on menopause that help fighting marginalisation and the reduction of menopause to a medicalised view. In the following, we discuss three intersecting ways in which HCI can further address menopause as a social justice matter: by supporting resistance of a medicalised view, by being close to the ever-changing body, and by including a plurality of bodies and experiences.

\subsection{Designing to resist the medicalisation of menopause}

Our results are in line with those of Perz et al. [78], who found that when women resisted a medicalised discourse, they conceptualised menopause as a time for transformation, self-growth and reflection on life priorities. A key concept to resistance to structural oppression is agency, and certainly the participants expressed their agency both in terms of resisting medicalisation, and by acknowledging their bodies and lived experiences. Participants had spent time and energy, sometimes over several years, in noticing and attuning to the changes they experienced, and in becoming experts in their own lived body, but this self-knowledge was ignored in a context of medicalisation. Nevertheless, participants questioned the authority of their doctors to 'diagnose' that 'everything is fine' when they felt it was not, shifting the power imbalance by trusting one's own body. The participants' strategies of addressing their wellbeing holistically also illustrates such agency. In particular, their existing bodily practices and material engagements with massage to relax muscles, ropes to jump, rolls to stretch their back, herbal teas to digest, and so on, constitute an active attitude to engaging with the body. In line with participatory approaches to design, we argue that it is worth looking at and learning from what people already do with the agency they have, probing into their responses to changes during the climacteric, instead of seeing them as passive consumers of products to hide the public aspects of bodily experiences.

Our analysis has shown that technological interventions for menopause should value people's own body knowledge and material engagements, as keys to support them in resisting medicalisation. Participants' concepts show how technology can start addressing this. For example, the cocoon does not get rid of bodily anxiety and does not pose it as something to be cured: The bodily anxiety is still there and it is still experienced, but the design allows the person to engage with this feeling in the process of accepting it, rather than fighting or going against it. As Kerstin puts it: "I just want to be with the body, be with the experience, let it run its course". Interestingly, being with the experience might actually mean touching the experience, in both a physical and a symbolic way. When Kerstin reflected about the movements that would bring the water up in the cocoon, she referred to them as physically "touching my own breathing" and related it with Feldenkrais-inspired movements: "You start by exploring your lungs from the inside and then you explore your lungs from the outside, touching yourself, touching your rhythms, or somebody else's rhythms". From Kerstin's words we can see that the cocoon, while avoiding to solve the bodily anxiety, still touches the experience: "Accepting the experience, letting it be what it is, but having a design that lets me acknowledge that it is there would be enough to transform it". Similarly, the spike mat, although addressing a concrete physical experience, is not designed to mediate between a patient and a doctor, often posited as a user and an expert. Instead, it is a technology that comes close to the body, reacting to pain, avoiding to wake up the wearer and supporting them in prioritising rest and relaxation.

But, resisting medicalisation is not simply shifting the responsibility from doctors to patients to keep healthy, it is instead about dismantling altogether the role of people going through menopause as patients. Moreover, avoiding to increase individual burden is key 
for effectively resisting the medicalisation of human experiences [27]. Resisting medicalisation, then, should not stop at questioning what Conrad and Schneider [24] called the doctor-patient interaction level, and must also question the institutional level. Existing work in health activism can provide a starting point. Grimes Parker [42] argued for looking beyond individual behaviour change, to instead consider how activism is required to change the social and environmental structures that lead to inequalities, while taking into account the limited choice that people may have. This approach is enacted in the context of breastfeeding by FeedFinder [6], a community-based app for sharing experiences of public breastfeeding spaces.

A necessary step to avoid burdening the individual when designing technology for menopause is carefully considering the time and the space where such technology could be used. Participants devised the cocoon and the spike mat to be used in the home rather than in a medical context, which can be seen as a first step towards resisting medicalisation. This trend has been seen in $\mathrm{HCI}$ in the context of fertility tracking [47] and gut tracking [17]. However, taking the home for granted as a space for interaction can be problematic. In our interview data, some participants wanted to engage in bodily practices such as yoga and meditation, but did not have the time in their busy schedules as workers and mothers. Moreover, workshop participants openly recognised that the home, during daily activities, is not a completely free space for being 'the new introvert me'. This realisation sparked a conversation about the role of employers in the menopause transition: What if the workplace could provide a time and a space for engaging with the body? Existing literature on menopause and the workplace, such as [39, 41, 45, 54], might give starting points for designers to explore this matter. What would it look like and how could people going through menopause participate in the creation and ownership of these spaces? The redesign of public spaces (e.g., restrooms) for safe experiences of menstruation was examined by Tuli et al. [96] and might serve as an inspiration. On the other hand, if the home could be reclaimed as a fruitful space, future work could explore together with participants what are the best moments in the day or in the week for making time for oneself. For example, morning rituals -such as Alicia's routine of breathing with eyes closed for five minutes while feeling her feet on the floor-, or night rituals, can be evocative paths to follow. Desjardins et al.'s [31] work on non-stereotypical homes could help in broadening uses and users of the home. In particular, researchers could pursue these authors' ideas on extending temporality (e.g., capturing and re-living past stories of menopause in the home) and revisiting agency (e.g., probing into how domestic objects could further support people's agency).

In summary, we argue that HCI should lead the shift from technology that risks to further the medicalisation of menopause, to technology that accompanies people in resisting such medicalisation without burdening the individual.

\subsection{Designing close to the ever-changing body}

Our data shows that making space for experiences of menopause comprises not just acknowledging them, but also transforming them. This acknowledgement involves accepting the body as it changes but it does not end there: wilful acceptance of the body can be a motor for transforming menopause experiences -even when, as in Kerstin's case, it is seemingly used only to support the decision of staying with and flowing through uncomfortable bodily experiences. The interviews abounded in details on attuning to the body, cultivating trust, noticing and being grateful for 'what works', appreciating and caring for the body. However, participants struggled with experiences that stemmed from the internalisation of patriarchal and ageist values -such as judging oneself based on youth and beauty standards, which turned body shape change into a frustrating experience that questioned self-esteem, and hot flushes into embarrassing episodes. Our data illustrates the entanglement between societal values and subjective experience, but we avoid the risk of an "oversocialised conception of women" [11]. We call HCI to support people in becoming aware of the internalisation of such values, in accepting and reclaiming their own bodily experiences during menopause, to then appreciate the body and fuel appreciation and compassion in others, similar to Campo Woytuk et al.'s [20] take on menstrual cycles.

Participants' design concepts start showing how design can be close to the body to make space for menopause experiences. A curious aspect of these concepts is their intimate nature -due to their closeness to the body- and their link with the night, a time when participants are either alone or with a significant other, rather than 'on stage' at work or in public spaces. Participants chose to situate the designs in a context that highly contrasts with the values driving commercial products that aim at controlling and even hiding experiences that can be seen by others, such as daytime hot flushes and sweat. When prompted to pick meaningful experiences of menopause, participants did not choose to design artefacts that allow them to stay elegant and fresh in front of an audience: They valued a good night sleep, a safe space, a holistic feeling of wellbeing. The cocoon and the spike mat illustrate how design can engage with wellbeing in a holistic way that does not isolate the body from the context in which it lives, while reclaiming its centrality. These design concepts conjugate the feelings of anxiety in the throat and chest, on the skin, the pain, the seemingly contradiction in contracting and releasing, the need of stretching and embracing, of making space for a new introvert self, of giving permission to oneself, of slowing down and resting, of living and flowing with pleasurable and uncomfortable experiences of menopause, riding the waves. In contrast with the values enacted by industry and the biomedical discourse, these design concepts do not try to get rid of menopause experiences, nor to conceal, quantify, classify, or control them. Importantly, these design concepts do not have acceptance of menopause experiences and of the changing body as an idealised end goal, but as a value, a premise for design. Participants departed from a deliberate choice of accepting the existence of these experiences, and the desire of acknowledging them, and through this recognition, touching the experiences and transforming with them.

We show one possible way in which interaction design can work against the medicalisation of menopause by reclaiming the everchanging body and promoting appreciation for it. We believe that the field of HCI can concretely deepen this approach. What if interaction designers engaged with people going through menopause who struggle to find body positivity [89]? What if, instead of creating fitness trackers that measure success in terms of lost weight, we engage with the ever changing shape of the body, finding value 
in it, celebrating -in Kerstin's words- the 'caterpillar' not just the 'butterfly'? What would the opposite of shapewear look and feel like? Designers could be engaging with experiences of muscle and joint pain, elasticity of the skin, vaginal dryness, or with other bodily-rooted changes that are meaningful for people during the menopause transition. Here a crucial tension arises: How to design to be close to the body, when people's appreciation for their body is critically low, or when they are not ready or not able to be close to the body? Recognising the joys and the challenges of deeply somatic experiences is key when designing for menopause, and has been explored by Devendorf et al. [32] through extremely personal items that illustrate the complexities of motherhood in a way that embraces uncertainty and contradiction. Similarly, $\mathrm{Ng}$ et al. [74] analysed the use of workshops and design to encourage women to experience their bodies differently when menstruating.

We respond to Höök et al.s [49] call on designing for changing bodies by engaging with menopause, a time particularly rich in change, without overlooking that design should always question assumptions of an ideal, immutable body throughout life. What would it mean to build technology that addresses the long-term aspect of the climacteric, its fuzzy extremes, and a self-knowledge acquired slowly and often acknowledged in retrospective? Moreover, with menstruators' lives traditionally divided into three stages, with menarche and menopause as thresholding markers, what role could technology play in questioning these markers in the context of resisting the medicalisation of reproductive life? What about the liminality [100], the unlabelled moments in between? For example, slow technology $[43,76]$ could accompany people throughout the climacteric inviting reflection. The spike mat could play the role, at the beginning, of easing joint and muscle pain, and then slowly transition throughout months or years, reducing its own intensity towards a soft, subtle massage, as it learns the wearer's sleeping and pain patterns. The cocoon could also learn from use and start initiating a gentle, playful push and not just providing relief. Wallace et al.'s [101] ReFind could inspire a version of the cocoon to revisit the bodily experiences with menopause of a loved one, after capturing their felt experiences [16].

In summary, we see opportunities for $\mathrm{HCI}$ to shift from technology that avoids the body by modeling it, reducing it to numbers and controlling or denying its experiences, towards technology that actually engages with the body and its short- and long-term processes, elevating and appreciating a mutable body that does not suddenly become meaningful after 12 months without menstruation, but that changes throughout the whole climacteric, and throughout life.

\subsection{Designing with a plurality of menopause and midlife experiences}

In this paper, we report on our first steps to building partnerships taking a feminist, inclusive stance that did not constrain gender nor age for recruitment, and that tried to reach out to people from different origins and social classes within a Scandinavian context. Despite our efforts to engage a more diverse sample, survey respondents were all cisgender women, from which most were in a relationship and had non-induced experiences of menopause. All thirteen participants were heterosexual, mothers, and workers, raised in Western contexts. We contacted local human rights and
LGBTQIA+ organisations but unfortunately, no candidates got in contact with us through these channels. This reminds us that reaching out is not enough and that initiating partnerships around such delicate topics requires working hard to collectively ensure proper conditions for participation. For example, during recruitment we found Facebook groups about menopause that explicitly exclude trans women in their descriptions, and that completely ignore trans men and non-binary folks. It is clear that creating safe spaces for participants implies cultivating our own expertise and skills [58]. But perhaps more importantly, we wonder: Is menopause actually the right topic within the context of midlife health when considering communities with multiple layers of stigmatisation? To start addressing the gap in participation, HCI researchers should set an agenda with participants and organisations to find topics that are meaningful for them, in order to support advocacy and pluralism at the same time.

\section{CONCLUSION}

In this paper, we reclaim the body through design in order to resist the medicalisation of menopause, as an enactment of social justice in everyday life. Through an interview study and a design workshop, we started cultivating partnerships with thirteen participants. Our data highlights experiences of menopause as bodily-rooted and socially-shaped. Participants created design concepts that closely interact with the body as a means of making space for experiences of menopause, supporting physical and symbolic touching.

When first engaging with menopause in this research, we were surprised to find an apparent natural part of life still surrounded by so much silence and generalised disinterest. We found ourselves immersed in and fascinated by participants' accounts of this life transition, which intertwined struggle and joy. We might ask, then, how would menopause be experienced in a more feminist future? We believe that engaging the body in designing to resist the medicalisation of menopause is indeed a path towards building such a future.

\section{ACKNOWLEDGMENTS}

We deeply thank participants for sharing their story with us. We are also grateful to the Interaction Design team at MID (KTH) for their support and feedback. This work was partially funded by the Swedish Research Council project 2017-05133.

\section{REFERENCES}

[1] Teresa Almeida, Rob Comber, and Madeline Balaam. 2016. HCI and Intimate Care as an Agenda for Change in Women's Health. In Proceedings of the 2016 CHI Conference on Human Factors in Computing Systems (San Jose, California, USA) (CHI '16). Association for Computing Machinery, New York, NY, USA, 2599-2611. https://doi.org/10.1145/2858036.2858187

[2] Teresa Almeida, Rob Comber, Gavin Wood, Dean Saraf, and Madeline Balaam. 2016. On Looking at the Vagina through Labella. In Proceedings of the 2016 CHI Conference on Human Factors in Computing Systems (San Jose, California, USA) (CHI '16). Association for Computing Machinery, New York, NY, USA, 1810-1821. https://doi.org/10.1145/2858036.2858119

[3] Elham Amini and Mark McCormack. 2019. Medicalization, menopausal time and narratives of loss: Iranian Muslim women negotiating gender, sexuality and menopause in Tehran and Karaj. Women's Studies International Forum 76 (2019), 102277. https://doi.org/10.1016/j.wsif.2019.102277

[4] Nancy E Avis, Rebecca Stellato, Sybil Crawford, Joyce Bromberger, Patricia Ganz, Virginia Cain, and Marjorie Kagawa-Singer. 2001. Is there a menopausal syndrome? Menopausal status and symptoms across racial/ethnic groups. Social science \& medicine 52, 3 (2001), 345-356. 
[5] Beverley Ayers, Mark Forshaw, and Myra S. Hunter. 2010. The impact of attitudes towards the menopause on women's symptom experience: A systematic review. Maturitas 65, 1 (2010), 28-36. https://doi.org/10.1016/j.maturitas.2009.10.016

[6] Madeline Balaam, Rob Comber, Ed Jenkins, Selina Sutton, and Andrew Garbett. 2015. FeedFinder: A Location-Mapping Mobile Application for Breastfeeding Women. In Proceedings of the 33rd Annual ACM Conference on Human Factors in Computing Systems (Seoul, Republic of Korea) (CHI '15). Association for Computing Machinery, New York, NY, USA, 1709-1718. https://doi.org/10. $1145 / 2702123.2702328$

[7] Madeline Balaam, Nadia Campo Woytuk, Marianela Ciolfi Felice, Ozgun Kilic Afsar, Anna Ståhl, and Marie Louise Juul Søndergaard. 2020. Intimate touch. Interactions 27, 6 (Nov. 2020), 14-17. https://doi.org/10.1145/3427781

[8] Karen D. Ballard, Diana J. Kuh, and Michael E.J. Wadsworth. 2001. The role of the menopause in women's experiences of the 'change of life'. Sociology of Health and Illness 23, 4 (2001), 397-424. https://doi.org/10.1111/1467-9566.00258

[9] Jeffrey Bardzell, Shaowen Bardzell, Amanda Lazar, and Norman Makoto Su. 2019. (Re-)Framing Menopause Experiences for HCI and Design. In Proceedings of the 2019 CHI Conference on Human Factors in Computing Systems (Glasgow, Scotland Uk) (CHI '19). Association for Computing Machinery, New York, NY, USA, 1-13. https://doi.org/10.1145/3290605.3300345

[10] Shaowen Bardzell. 2010. Feminist HCI: Taking Stock and Outlining an Agenda for Design. In Proceedings of the SIGCHI Conference on Human Factors in Computing Systems (Atlanta, Georgia, USA) (CHI '10). Association for Computing Machinery, New York, NY, USA, 1301-1310. https://doi.org/10.1145/1753326. 1753521

[11] Diane Beeson. 1975. Women in studies of aging: a critique and suggestion. Social Problems 23, 1 (1975), 52-59.

[12] Susan E. Bell. 1987. Changing ideas: The medicalization of menopause. Social Science and Medicine 24, 6 (1987), 535-542. https://doi.org/10.1016/0277-9536(87) 90343-1

[13] Cynthia L. Bennett and Daniela K. Rosner. 2019. The Promise of Empathy: Design, Disability, and Knowing the "Other". In Proceedings of the $2019 \mathrm{CH}$ Conference on Human Factors in Computing Systems (Glasgow, Scotland Uk) (CHI '19). Association for Computing Machinery, New York, NY, USA, 1-13. https://doi.org/10.1145/3290605.3300528

[14] Ilias Bergström and Martin Jonsson. 2016. Sarka: Sonification and Somaesthetic Appreciation Design. In Proceedings of the 3rd International Symposium on Movement and Computing (Thessaloniki, GA, Greece) (MOCO '16). Association for Computing Machinery, New York, NY, USA, Article 1, 8 pages. https //doi.org/10.1145/2948910.2948922

[15] C. Berterö. 2003. What do women think about menopause? A qualitative study of women's expectations, apprehensions and knowledge about the climacteric period. International nursing review 50, 2 (2003), 109-18. http://www.ncbi.nlm. nih.gov/pubmed/12752910

[16] Janne Mascha Beuthel and Danielle Wilde. 2017. Wear.x: Developing Wearables That Embody Felt Experience. In Proceedings of the 2017 Conference on Designing Interactive Systems (Edinburgh, United Kingdom) (DIS '17). Association for Computing Machinery, New York, NY, USA, 915-927. https://doi.org/10.1145/ 3064663.3064799

[17] Laurens Boer, Harvey Bewley, Tom Jenkins, Sarah Homewood, Teresa Almeida, and Anna Vallgårda. 2020. Gut-Tracking as Cultivation. In Proceedings of the 2020 ACM Designing Interactive Systems Conference (Eindhoven, Netherlands) (DIS '20). Association for Computing Machinery, New York, NY, USA, 561-574. https://doi.org/10.1145/3357236.3395588

[18] Nancy L Booth, Colleen E Piersen, Suzanne Banuvar, Stacie E Geller, Lee P Shulman, and Norman R Farnsworth. 2006. Clinical studies of red clover (Trifolium pratense) dietary supplements in menopause: a literature review. Menopause 13, 2 (2006), 251-264

[19] Virginia Braun and Victoria Clarke. 2006. Using thematic analysis in psychology. Qualitative Research in Psychology 3, 2 (2006), 77-101. https://doi.org/10.1191/ 1478088706qp063oa

[20] Nadia Campo Woytuk, Marie Louise Juul Søndergaard, Marianela Ciolfi Felice, and Madeline Balaam. 2020. Touching and Being in Touch with the Menstruating Body. In Proceedings of the 2020 CHI Conference on Human Factors in Computing Systems (Honolulu, HI, USA) (CHI '20). Association for Computing Machinery, New York, NY, USA, 1-14. https://doi.org/10.1145/3313831.3376471

[21] Camil Castelo-Branco, Santiago Palacios, Desiree Mostajo, Cristina Tobar, and Sueli Von Helde. 2005. Menopausal transition in Movima women, a Bolivian native-American. Maturitas 51, 4 (2005), 380-385. https://doi.org/10.1016/j. maturitas.2004.09.004

[22] Joan C. Chrisler. 2011. Leaks, lumps, and lines: Stigma and women's bodies. Psychology of Women Quarterly 35, 2 (2011), 202-214. https://doi.org/10.1177/ 0361684310397698

[23] Andri Christoforou. 2018. Uncontrollable bodies: Greek Cypriot women talk about the transition to menopause. Women's Studies International Forum 70 July 2016 (2018), 9-16. https://doi.org/10.1016/j.wsif.2018.07.009

[24] Peter Conrad and Joseph W Schneider. 1980. Looking at levels of medicalization: a comment on Strong's critique of the thesis of medical imperialism. Social
Science \& Medicine. Part A: Medical Psychology \& Medical Sociology 14, 1 (1980), $75-79$.

[25] Loree Cook-Daniels and Michael Munson. 2010. Sexual violence, elder abuse, and sexuality of transgender adults, age 50+: Results of three surveys. Fournal of GLBT Family Studies 6, 2 (2010), 142-177. https://doi.org/10.1080/ 15504281003705238

[26] Jamie Cooper. 2018. Examining factors that influence a woman's search for information about menopause using the socio-ecological model of health promotion. Maturitas 116 (2018), 73-78. https://doi.org/10.1016/j.maturitas.2018.07.013

[27] Robert Crawford. 1980. Healthism and the medicalization of everyday life. International journal of health services 10, 3 (1980), 365-388.

[28] Isabel de Salis, Amanda Owen-Smith, Jenny L. Donovan, and Debbie A. Lawlor. 2018. Experiencing menopause in the UK: The interrelated narratives of normality, distress, and transformation. Journal of Women and Aging 30, 6 (2018), 520-540. https://doi.org/10.1080/08952841.2018.1396783

[29] Daniel Delanoë, Selma Hajri, Annie Bachelot, Dorra Mahfoudh Draoui, Danielle Hassoun, Elise Marsicano, and Virginie Ringa. 2012. Class, gender and culture in the experience of menopause. A comparative survey in Tunisia and France. Social Science and Medicine 75, 2 (2012), 401-409. https://doi.org/10.1016/j. socscimed.2012.02.051

[30] Paula S. Derry. 2002. What do we mean by "the biology of menopause"? Sex Roles 46Derry, P, 1-2 (2002), 13-23. https://doi.org/10.1023/A:1016081400820

[31] Audrey Desjardins, Jeremy E. Viny, Cayla Key, and Nouela Johnston. 2019. Alternative Avenues for IoT: Designing with Non-Stereotypical Homes. In Proceedings of the 2019 CHI Conference on Human Factors in Computing Systems (Glasgow, Scotland Uk) (CHI '19). Association for Computing Machinery, New York, NY, USA, 1-13. https://doi.org/10.1145/3290605.3300581

[32] Laura Devendorf, Kristina Andersen, and Aisling Kelliher. 2020. The Fundamental Uncertainties of Mothering: Finding Ways to Honor Endurance, Struggle, and Contradiction. ACM Trans. Comput.-Hum. Interact. 27, 4, Article 26 (Sept. 2020), 24 pages. https://doi.org/10.1145/3397177

[33] Heather Dillaway. 2008. "Why Can't You Control This?" How Women's Interactions with Intimate Partners Define Menopause and Family. Fournal of women \& aging 20 (02 2008), 47-64. https://doi.org/10.1300/J074v20n01_05

[34] Heather Dillaway. 2020. Living in Uncertain Times: Experiences of Menopause and Reproductive Aging. Springer Singapore, Singapore, 253-268. https://doi. org/10.1007/978-981-15-0614-7_21

[35] Heather E. Dillaway. 2005. (Un)changing menopausal bodies: How women think and act in the face of a reproductive transition and gendered beauty ideals. Sex Roles 53, 1-2 (2005), 1-17. https://doi.org/10.1007/s11199-005-4269-6

[36] Heather E. Dillaway. 2016. Menopause: Deficiency Disease or Normal Reproductive Transition? In The Wrong prescription for women: How medicine and media create a "need" for treatments, drugs, and surgery. Praeger, Santa Barbara, California, 53-2229-53-2229. https://doi.org/10.5860/choice.193859

[37] Joan Engebretson and Diane Wind Wardell. 1997. Perimenopausal women's alienation. Journal of holistic Nursing 15, 3 (1997), 254-270.

[38] Moshe Feldenkrais. 1972. Awareness through movement. Vol. 1977. Harper and Row, New York.

[39] Emília Fernandes and Regina Leite. 2016. Embodied women in the work context: The case of Portuguese businesswomen and their female subordinates. Women's Studies International Forum 56 (2016), 45-55. https://doi.org/10.1016/j.wsif.2015. 12.005

[40] Sarah Fox. 2018. Design, Maintenance, and the Menstruating Body. In Proceedings of the 2018 ACM Conference Companion Publication on Designing Interactive Systems (Hong Kong, China) (DIS '18 Companion). Association for Computing Machinery, New York, NY, USA, 375-378. https://doi.org/10.1145/3197391. 3205386

[41] Amanda Griffiths, Sara Jane MacLennan, and Juliet Hassard. 2013. Menopause and work: An electronic survey of employees' attitudes in the UK. Maturitas 76, 2 (2013), 155-159. https://doi.org/10.1016/j.maturitas.2013.07.005

[42] Andrea Grimes Parker. 2013. Designing for Health Activism. Interactions 20, 2 (March 2013), 22-25. https://doi.org/10.1145/2427076.2427082

[43] Lars Hallnäs and Johan Redström. 2001. Slow technology-designing for reflection. Personal and ubiquitous computing 5, 3 (2001), 201-212.

[44] Doaa Hammoudeh, Ernestina Coast, David Lewis, Yoke van der Meulen, Tiziana Leone, and Rita Giacaman. 2017. Age of despair or age of hope? Palestinian women's perspectives on midlife health. Social Science and Medicine 184 (2017), 108-115. https://doi.org/10.1016/j.socscimed.2017.05.028

[45] Claire Hardy, Amanda Griffiths, and Myra S. Hunter. 2017. What do working menopausal women want? A qualitative investigation into women's perspectives on employer and line manager support. Maturitas 101, March (2017), 37-41. https://doi.org/10.1016/j.maturitas.2017.04.011

[46] Sarah Homewood. 2019. Inaction as a Design Decision: Reflections on Not Designing Self-Tracking Tools for Menopause. In Extended Abstracts of the 2019 CHI Conference on Human Factors in Computing Systems (Glasgow, Scotland Uk) (CHI EA '19). Association for Computing Machinery, New York, NY, USA, 1-12. https://doi.org/10.1145/3290607.3310430 
[47] Sarah Homewood, Harvey Bewley, and Laurens Boer. 2019. Ovum: Designing for Fertility Tracking as a Shared and Domestic Experience. In Proceedings of the 2019 on Designing Interactive Systems Conference (San Diego, CA, USA) (DIS '19). Association for Computing Machinery, New York, NY, USA, 553-565. https://doi.org/10.1145/3322276.3323692

[48] Kristina Höök. 2018. Designing with the Body: Somaesthetic Interaction Design MIT Press, Cambridge, Massachusetts. https://doi.org/10.5753/ihc.2018.4168

[49] Kristina Höök, Sara Eriksson, Marie Louise Juul Søndergaard, Marianela Ciolfi Felice, Nadia Campo Woytuk, Ozgun Kilic Afsar, Vasiliki Tsaknaki, and Anna Ståhl. 2019. Soma Design and Politics of the Body. In Proceedings of the Halfway to the Future Symposium 2019 (Nottingham, United Kingdom) (HTTF 2019). Association for Computing Machinery, New York, NY, USA, Article 1 , 8 pages. https://doi.org/10.1145/3363384.3363385

[50] Alexis Hope, Catherine D'Ignazio, Josephine Hoy, Rebecca Michelson, Jennifer Roberts, Kate Krontiris, and Ethan Zuckerman. 2019. Hackathons as Participatory Design: Iterating Feminist Utopias. In Proceedings of the $2019 \mathrm{CHI}$ Conference on Human Factors in Computing Systems (Glasgow, Scotland Uk) (CHI '19). Association for Computing Machinery, New York, NY, USA, 1-14. https://doi.org/10.1145/3290605.3300291

[51] Lotte Hvas. 2001. Positive aspects of menopause - A qualitative study. Maturitas 39, 1 (2001), 11-17. https://doi.org/10.1016/S0378-5122(01)00184-0

[52] Abbey Hyde, Jean Nee, Etaoine Howlett, Jonathan Drennan, and Michelle Butler 2010. Menopause narratives: The interplay of womens embodied experiences with biomedical discourses. Qualitative Health Research 20, 6 (2010), 805-815. https://doi.org/10.1177/1049732310363126

[53] Rita Ismail, Lauri A. Linder, Catherine Fiona Macpherson, and Nancy Fugate Woods. 2016. Feasibility of an iPad application for studying menopause-related symptom clusters and womens heuristics. Informatics for Health and Social Care 41, 3 (2016), 247-266. https://doi.org/10.3109/17538157.2015.1008489

[54] Gavin Jack, Kathleen Riach, Emily Bariola, Marian Pitts, Jan Schapper, and Philip Sarrel. 2016. Menopause in the workplace: What employers should be doing Maturitas 85, September 2014 (2016), 88-95. https://doi.org/10.1016/j.maturitas. 2015.12.006 arXiv:0209013 [cs]

[55] Hilary Janks. 2014. The importance of critical literacy. Moving critical literacies forward: A new look at praxis across contexts 11, 1 (2014), 32-44.

[56] Kaufert. 1998. Women and menopause: Beliefs, attitudes, and behaviors. Menopause: The journal of the North American Menopause Society 5, 4 (1998), 197-202. https://doi.org/10.1097/00042192-199805040-00001

[57] Patricia A. Kaufert. 1982. Anthropology and the menopause: the development of a theoretical framework. Maturitas 4, 3 (1982), 181-193. https://doi.org/10. 1016/0378-5122(82)90048-2

[58] Os Keyes, Burren Peil, Rua M. Williams, and Katta Spiel. 2020. Reimagining (Women's) Health: HCI, Gender and Essentialised Embodiment. ACM Trans. Comput.-Hum. Interact. 27, 4, Article 25 (Aug. 2020), 42 pages. https://doi.org/ $10.1145 / 3404218$

[59] George Khut. 2006. Development and evaluation of participant-centred biofeedback artworks (Unpublished doctoral exegesis). Ph.D. Dissertation. University of Western Sydney.

[60] Sabine Krajewski. 2019. Advertising menopause: you have been framed. Con tinuum 33, 1 (2019), 137-148. https://doi.org/10.1080/10304312.2018.1547364

[61] Amanda Lazar, Norman Makoto Su, Jeffrey Bardzell, and Shaowen Bardzell. 2019. Parting the Red Sea: Sociotechnical Systems and Lived Experiences of Menopause. In Proceedings of the 2019 CHI Conference on Human Factors in Computing Systems (Glasgow, Scotland Uk) (CHI '19). Association for Computing Machinery, New York, NY, USA, 1-16. https://doi.org/10.1145/3290605.3300710

[62] Mirim Lee, Bon-chang Koo, Hee-seok Jeong, Joongsing Park, Juhee Cho, and Jundong Cho. 2015. Designing MHealth Intervention for Women in Menopausal Period. In Proceedings of the 9th International Conference on Pervasive Comput ing Technologies for Healthcare (Istanbul, Turkey) (PervasiveHealth '15). ICST (Institute for Computer Sciences, Social-Informatics and Telecommunications Engineering), Brussels, BEL, 257-260.

[63] Wonjun Lee, Youn-kyung Lim, and Richard Shusterman. 2014. Practicing Somaesthetics: Exploring Its Impact on Interactive Product Design Ideation. In Proceedings of the 2014 Conference on Designing Interactive Systems (Vancouver BC, Canada) (DIS '14). Association for Computing Machinery, New York, NY, USA, 1055-1064. https://doi.org/10.1145/2598510.2598561

[64] Lotta Lindh-Åstrand, Jan Brynhildsen, Mikael Hoffmann, Susanne Liffner, and Mats Hammar. 2007. Attitudes towards the menopause and hormone therapy over the turn of the century. Maturitas 56, 1 (2007), 12-20. https://doi.org/10. 1016/j.maturitas.2006.05.002

[65] Margaret Lock. 1985. Models and Practice in Medicine: Menopause as Syndrome or Life Transition? In Physicians of Western Medicine. Springer, Dordrecht. https://doi.org/10.1007/978-94-009-6430-3

[66] Margaret Lock and Patricia Kaufert. 2001. Menopause, local biologies, and cultures of aging. American fournal of Human Biology 13, 4 (2001), 494-504 https://doi.org/10.1002/ajhb.1081

[67] Lian Loke and George Poonkhin Khut. 2010. Surging Verticality: An Experience of Balance. In Proceedings of the Fifth International Conference on Tangible,
Embedded, and Embodied Interaction (Funchal, Portugal) (TEI '11). Association for Computing Machinery, New York, NY, USA, 237-240. https://doi.org/10. 1145/1935701.1935747

[68] Lian Loke, George Poonkhin Khut, and A. Baki Kocaballi. 2012. Bodily Experience and Imagination: Designing Ritual Interactions for Participatory Live-Art Contexts. In Proceedings of the Designing Interactive Systems Conference (Newcastle Upon Tyne, United Kingdom) (DIS '12). Association for Computing Machinery, New York, NY, USA, 779-788. https://doi.org/10.1145/2317956.2318073

[69] Lian Loke, George Poonkhin Khut, Maggie Slattery, Catherine Truman, Lizzie Muller, and Jonathan Duckworth. 2013. Re-sensitising the body: interactive art and the Feldenkrais method. International Journal of Arts and Technology 6, 4 (2013), 339-356.

[70] Lian Loke and Thecla Schiphorst. 2018. The somatic turn in human-computer interaction. Interactions 25, 5 (2018), 54-5863.

[71] G.B. Mahady, A.L. Perez, S.M. Wicks, B.J. Doyle, and T.D. Locklear. 2017. Menopause in Latin America: Symptoms, attitudes, treatments and future directions in Costa Rica. Maturitas 104, July (2017), 84-89. https://doi.org/10.1016/j. maturitas.2017.07.008

[72] Joanna L. Michel, Gail B. Mahady, Mario Veliz, Doel D. Soejarto, and Armando Caceres. 2006. Symptoms, attitudes and treatment choices surrounding menopause among the Q'eqchi Maya of Livingston, Guatemala. Social Science and Medicine 63, 3 (2006), 732-742. https://doi.org/10.1016/j.socscimed.2006.02. 010

[73] Sophie Mohamed and Myra S. Hunter. 2019. Transgender women's experiences and beliefs about hormone therapy through and beyond mid-age: An exploratory UK study. International fournal of Transgenderism 20, 1 (2019), 98-107. https: //doi.org/10.1080/15532739.2018.1493626

[74] Sarah Ng, Shaowen Bardzell, and Jeffrey Bardzell. 2020. The Menstruating Entrepreneur Kickstarting a New Politics of Women's Health. ACM Transactions on Computer-Human Interaction (TOCHI) 27, 4 (2020), 1-25.

[75] Marcianna Nosek, Holly Powell Kennedy, Yewoubdar Beyene, Diana Taylor, Catherine Gilliss, and Kathryn Lee. 2010. The Effects of Perceived Stress and Attitudes Toward Menopause and Aging on Symptoms of Menopause. Fournal of Midwifery and Women's Health 55, 4 (2010), 328-334. https://doi.org/10.1016/ j.jmwh.2009.09.005

[76] William Odom, Richard Banks, Abigail Durrant, David Kirk, and James Pierce. 2012. Slow Technology: Critical Reflection and Future Directions. In Proceedings of the Designing Interactive Systems Conference (Newcastle Upon Tyne, United Kingdom) (DIS '12). Association for Computing Machinery, New York, NY, USA, 816-817. https://doi.org/10.1145/2317956.2318088

[77] S. Palacios, V. W. Henderson, N. Siseles, D. Tan, and P. Villaseca. 2010. Age of menopause and impact of climacteric symptoms by geographical region. Climacteric 13, 5 (2010), 419-428. https://doi.org/10.3109/13697137.2010.507886

[78] Janette Perz and Jane M. Ussher. 2008. "The horror of this living decay": Women's negotiation and resistance of medical discourses around menopause and midlife. Women's Studies International Forum 31, 4 (2008), 293-299. https://doi.org/10. 1016/j.wsif.2008.05.003

[79] Tamara Peyton, Erika Poole, Madhu Reddy, Jennifer Kraschnewski, and Cynthia Chuang. 2014. "Every Pregnancy is Different": Designing MHealth for the Pregnancy Ecology. In Proceedings of the 2014 Conference on Designing Interactive Systems (Vancouver, BC, Canada) (DIS '14). Association for Computing Machinery, New York, NY, USA, 577-586. https://doi.org/10.1145/2598510.2598572

[80] Agatha A. Quinn. 1991. A Theoretical model of the perimenopausal process. Journal of Nurse-Midwifery 36, 1 (1991), 25 - 29. https://doi.org/10.1016/00912182(91)90018-K

[81] Sharon S Rostosky and Cheryl Brown Travis. 2000. Menopause and sexuality: Ageism and sexism unite. In Sexuality, society, and feminism. American Psychological Association, Washington, DC, US, 181-209. https://doi.org/10.1037/ 10345-008

[82] Thecla Schiphorst. 2011. Self-Evidence: Applying Somatic Connoisseurship to Experience Design. In CHI '11 Extended Abstracts on Human Factors in Computing Systems (Vancouver, BC, Canada) (CHI EA '11). Association for Computing Machinery, New York, NY, USA, 145-160. https://doi.org/10.1145/1979742. 1979640

[83] Britta F. Schulte, Kellie Morrissey, Marie Louise Juul Søndergaard, and Rens Brankaert. 2020. Don't Blush: Sexuality, Aging \& Design. In Companion Publication of the 2020 ACM Designing Interactive Systems Conference (Eindhoven, Netherlands) (DIS' 20 Companion). Association for Computing Machinery, New York, NY, USA, 405-408. https://doi.org/10.1145/3393914.3395915

[84] Caterina Senette, Maria Claudia Buzzi, Maria Teresa Paratore, and Amaury Trujillo. 2018. Persuasive Design of a Mobile Coaching App to Encourage a Healthy Lifestyle during Menopause. In Proceedings of the 17th International Conference on Mobile and Ubiquitous Multimedia (Cairo, Egypt) (MUM 2018). Association for Computing Machinery, New York, NY, USA, 47-58. https: //doi.org/10.1145/3282894.3282899

[85] Richard Shusterman. 2008. Body consciousness: A philosophy of mindfulness and somaesthetics. Cambridge University Press, Cambridge. 
[86] Anna Siverskog. 2015. Ageing Bodies that Matter: Age, Gender and Embodiment in Older Transgender People's Life Stories. NORA - Nordic fournal of Feminist and Gender Research 23, 1 (2015), 4-19. https://doi.org/10.1080/08038740.2014.979869

[87] Marie Louise Juul Søndergaard and Lone Koefoed Hansen. 2016. PeriodShare: A Bloody Design Fiction. In Proceedings of the 9th Nordic Conference on HumanComputer Interaction (Gothenburg, Sweden) (NordiCHI '16). Association for Computing Machinery, New York, NY, USA, Article 113, 6 pages. https://doi. org/10.1145/2971485.2996748

[88] Marie Louise Juul Søndergaard, Ozgun Kilic Afsar, Marianela Ciolfi Felice, Nadia Campo Woytuk, and Madeline Balaam. 2020. Designing with Intimate Materials and Movements: Making "Menarche Bits". In Proceedings of the 2020 ACM Designing Interactive Systems Conference (Eindhoven, Netherlands) (DIS '20). Association for Computing Machinery, New York, NY, USA, 587-600. https://doi.org/10.1145/3357236.3395592

[89] Katta Spiel. 2019. Body-Positive Computing as a Means to Counteract Normative Biases in Fitness Trackers. XRDS 25, 4 (July 2019), 34-37. https://doi.org/10. $1145 / 3331065$

[90] Donna E. Stewart. 2003. Menopause in highland Guatemala Mayan women Maturitas 44, 4 (2003), 293-297. https://doi.org/10.1016/S0378-5122(03)00036-7

[91] Anna Ståhl, Martin Jonsson, Johanna Mercurio, Anna Karlsson, Kristina Höök, and Eva-Carin Banka Johnson. 2016. The Soma Mat and Breathing Light. In Proceedings of the 2016 CHI Conference Extended Abstracts on Human Factors in Computing Systems (San Jose, California, USA) (CHI EA '16). Association for Computing Machinery, New York, NY, USA, 305-308. https://doi.org/10.1145/ 2851581.2889464

[92] Ida Kilias Svenningsen and Teresa Almeida. 2020. Designing for the Emotional Pregnancy. In Companion Publication of the 2020 ACM Designing Interactive Systems Conference (Eindhoven, Netherlands) (DIS'20 Companion). Association for Computing Machinery, New York, NY, USA, 145-150. https://doi.org/10. $1145 / 3393914.3395897$

[93] Paul Tennent, Joe Marshall, Vasiliki Tsaknaki, Charles Windlin, Kristina Höök, and Miquel Alfaras. 2020. Soma Design and Sensory Misalignment. In Proceedings of the $2020 \mathrm{CHI}$ Conference on Human Factors in Computing Systems (Honolulu, HI, USA) (CHI '20). Association for Computing Machinery, New York, NY, USA, 1-12. https://doi.org/10.1145/3313831.3376812

[94] Amaury Trujillo and Maria Claudia Buzzi. 2016. Participatory User Requirements Elicitation for Personal Menopause App. In Proceedings of the 9th Nordic Conference on Human-Computer Interaction (Gothenburg, Sweden) (NordiCHI '16). Association for Computing Machinery, New York, NY, USA, Article 102 6 pages. https://doi.org/10.1145/2971485.2996737

[95] Amaury Trujillo and Maria Claudia Buzzi. 2018. Towards a Fuzzy Rule-Based Systems Approach for Adaptive Interventions in Menopause Self-Care. In Adjunct
Publication of the 26th Conference on User Modeling, Adaptation and Personalization (Singapore, Singapore) (UMAP '18). Association for Computing Machinery, New York, NY, USA, 53-56. https://doi.org/10.1145/3213586.3226193

[96] Anupriya Tuli, Shaan Chopra, Pushpendra Singh, and Neha Kumar. 2020. Menstrual (Im)Mobilities and Safe Spaces. In Proceedings of the 2020 CHI Conference on Human Factors in Computing Systems (Honolulu, HI, USA) (CHI '20). Association for Computing Machinery, New York, NY, USA, 1-15. https: //doi.org/10.1145/3313831.3376653

[97] Agatha Tutia, Kelda Baljon, Lan Vu, and Daniela K. Rosner. 2019. HCI and Menopause: Designing With and Around the Aging Body. In Extended Abstracts of the 2019 CHI Conference on Human Factors in Computing Systems (Glasgow, Scotland Uk) (CHI EA '19). Association for Computing Machinery, New York, NY, USA, 1-8. https://doi.org/10.1145/3290607.3299066

[98] Jane M Ussher, Alexandra J Hawkey, and Janette Perz. 2019. 'Age of despair', or 'when life starts': migrant and refugee women negotiate constructions of menopause. Culture, health \& sexuality 21, 7 (2019), 741-756.

[99] Rebecca L. Utz. 2011. Like mother, (not) like daughter: The social construction of menopause and aging. Fournal of Aging Studies 25, 2 (2011), 143-154. https: //doi.org/10.1016/j.jaging.2010.08.019

[100] Arnold Van Gennep. 2019. The rites of passage. University of Chicago Press, Chicago.

[101] Jayne Wallace, Kyle Montague, Trevor Duncan, Luís P. Carvalho, Nantia Koulidou, Jamie Mahoney, Kellie Morrissey, Claire Craig, Linnea Iris Groot, Shaun Lawson, Patrick Olivier, Julie Trueman, and Helen Fisher. 2020. ReFind: Design, Lived Experience and Ongoingness in Bereavement. In Proceedings of the 2020 CHI Conference on Human Factors in Computing Systems (Honolulu, HI, USA) (CHI '20). Association for Computing Machinery, New York, NY, USA, 1-12. https://doi.org/10.1145/3313831.3376531

[102] Robert W. Webster. 2002. Aboriginal women and menopause. Fournal of obstetrics and gynaecology Canada: 7OGC = fournal d'obstétrique et gynécologie du Canada : FOGC 24, 12 (2002), 938-940. https://doi.org/10.1016/S1701-2163(16)30591-6

[103] Julie A. Winterich and Debra Umberson. 1999. How Women Experience Menopause: The Importance of Social Context. Fournal of Women \& Aging 11, 4 (1999), 57-73. https://doi.org/10.1300/J074v11n04_05

[104] Tarynn M. Witten. 2009. Graceful exits: Intersection of aging, transgender identities, and the family/community. Fournal of GLBT Family Studies 5, 1-2 (2009), 35-61. https://doi.org/10.1080/15504280802595378

[105] Peter Wright, Jayne Wallace, and John McCarthy. 2008. Aesthetics and experience-centered design. ACM Transactions on Computer-Human Interaction (TOCHI) 15, 4 (2008), 1-21.

[106] Deepika Yadav, Prerna Malik, Kirti Dabas, and Pushpendra Singh. 2019. Feedpal: Understanding opportunities for chatbots in breastfeeding education of women in india. Proceedings of the ACM on Human-Computer Interaction 3, CSCW (2019), 1-30. 